\title{
Trends in the evolution to robot-assisted minimally invasive thoracoscopic esophagectomy
}

\author{
Jiajia Liu, Satoru Motoyama, Yusuke Sato, Akiyuki Wakita, Yuta Kawakita, Yushi Nagaki, Hiromu Fujita, \\ Kazuhiro Imai, Yoshihiro Minamiya
}

Esophageal Surgery, Akita University Hospital, Akita 010-0043, Japan.

Correspondence to: Dr. Satoru Motoyama, Esophageal Surgery, Akita University Hospital, 1-1-1 Hondo, Akita 010-8543, Japan. E-mail: motoyama@doc.med.akita-u.ac.jp

How to cite this article: Liu J, Motoyama S, Sato Y, Wakita A, Kawakita Y, Nagaki Y, Fujita H, Imai K, Minamiya Y. Trends in the evolution to robot-assisted minimally invasive thoracoscopic esophagectomy. Mini-invasive Surg 2020;4:44.

http://dx.doi.org/10.20517/2574-1225.2020.20

Received: 13 Feb 2020 First Decision: 1 Apr 2020 Revised: 30 Apr 2020 Accepted: 24 Jun 2020 Published: 19 Jul 2020

Academic Editor: Itasu Ninomiya Copy Editor: Cai-Hong Wang Production Editor: Jing Yu

\begin{abstract}
Much effort has been made to improve outcomes and/or minimize the invasiveness of esophagectomy for thoracic esophageal cancer. This has led to the evolution from open esophagectomy to thoracoscopic minimally invasive esophagectomy (MIE), and from MIE to robot-assisted minimally invasive esophagectomy (RAMIE). RAMIE is being applied clinically to overcome the limitations of MIE. In this article, we review the trends in the evolution from thoracoscopic MIE to RAMIE. It has now been demonstrated that RAMIE is both safe and feasible, and may decrease morbidity and mortality rates associated with esophagectomy and improve oncological outcomes. On the other hand, there are still many problems that need to be solved.
\end{abstract}

Keywords: Esophagectomy, esophageal cancer, robot-assisted esophagectomy, thoracoscopic esophagectomy

\section{INTRODUCTION}

Esophageal cancer is the 6th highest cause of cancer mortality worldwide due, in large part, to its high potential for metastasis ${ }^{[1]}$. The most reliable curative treatment is surgery entailing radical resection of the esophagus with extended lymphadenectomy in the mediastinum, abdomen, and neck. However, esophagectomy is associated with high postoperative morbidity (about $40 \%$ ) and mortality (about $3.4 \%)^{[2,3]}$. To improve outcomes, patients are often treated with multimodal treatments such as neoadjuvant

\footnotetext{
(ब) (1)

(C) The Author(s) 2020. Open Access This article is licensed under a Creative Commons Attribution 4.0 International License (https://creativecommons.org/licenses/by/4.0/), which permits unrestricted use, sharing, adaptation, distribution and reproduction in any medium or format, for any purpose, even commercially, as long as you give appropriate credit to the original author(s) and the source, provide a link to the Creative Commons license, and indicate if changes were made.
}

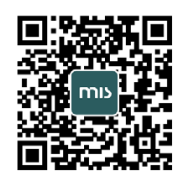


Table 1. RAMIE history

\begin{tabular}{ll}
\hline Year & \\
\hline 1960 s & Start of development of a remote operation system \\
1998 & DVSS enters clinical trials, first commercial sale \\
2000 & DVSS obtains Food and Drug Administration clearance \\
2001 & Performance of the first transatlantic surgery (robotic cholecystectomy) \\
2003 & The first transhiatal RAMIE \\
2004 & The first transthoracic RAMIE \\
\hline
\end{tabular}

DVSS: Da Vinci Surgical System; RAMIE: robot-assisted minimally invasive esophagectomy

chemotherapy or chemoradiotherapy, and there is much surgical effort towards improving operative techniques ${ }^{[4,5]}$. This has led to the evolution from open esophagectomy (OE) to thoracoscopic minimally invasive esophagectomy $(\mathrm{MIE})^{[6]}$, and from MIE to robot-assisted minimally invasive esophagectomy $(\text { RAMIE })^{[7]}$. Despite the many advantages of MIE, there are several associated limitations. RAMIE, which has advantages in terms of an enhanced three-dimensional magnified view, tremorless action, and articulated instruments, is being applied clinically to overcome the limitations of $\mathrm{MIE}^{[8]}$. In this article, we review the trends in the evolution from thoracoscopic esophagectomy to MIE and RAMIE.

\section{HISTORY OF RAMIE}

In the 1960s, the US Army and NASA began research on surgical robots with the aim of developing a remote operative system. It took nearly 30 years to complete the first fully functional surgical robot system. Called the Da Vinci Surgical System (DVSS), it has been clinically applied in the USA since 1997. In 1998, DVSS entered clinical trials and became commercially available in the USA. In 2000, DVSS was approved by the USA Food and Drug Administration. In 2001, a French surgeon, Jacques Marescaux, successfully performed the first transatlantic robotic-assisted cholecystectomy while working in the USA ${ }^{[9]}$. In 2003, Talamini et $a l^{[10]}$ reported the first series of transhiatal RAMIE. This was 8 years after the first transhiatal conventional MIE was reported by DePaula et al. ${ }^{[11]}$ in 1995. In 2004, Kernstine et al. ${ }^{[12]}$ reported the first series of transthoracic RAMIEs, which was 12 years after the first transthoracic conventional MIE was reported by Cuschieri et al. ${ }^{[6]}$ in 1992. Since then, RAMIE has been performed worldwide in many institutions. Moreover, given its many unique advantages, further clinical application of RAMIE is now being widely investigated. The history of RAMIE is summarized in Table 1.

\section{CHARACTERISTICS OF THE OPERATIVE APPROACHES TO ESOPHAGECTOMY}

MIE was introduced to improve outcomes and/or reduce the invasiveness of OE, and it has produced satisfactory results. In 2003, Luketich et al. ${ }^{[13]}$ reported the first large series of total MIEs and reported impressively low incidence of morbidity and mortality among 222 patients. Total MIE is performed by starting with a transthoracic MIE, followed by laparoscopic surgery to mobilize the stomach and perform upper abdominal lymphadenectomy. Transthoracic MIE provides improved magnified vision, less chest wall injury and relatively easy access to the upper thoracic structures, while laparoscopic surgery has less abdominal wall injury and less blood loss due to the pneumonic pressure. The first published randomized control trial in 2012, the TIME trial, is considered to be the cornerstone of MIE studies ${ }^{[14]}$. Between 2009 and 2017, eight meta-analyses were published, comparing postoperative and oncologic outcomes of MIE and $\mathrm{OE}^{[15]}$. MIE was generally found to be superior to $\mathrm{OE}$ in terms of intraoperative blood loss, acute immunological response, postoperative pulmonary infections, length of hospital stay, postoperative pain scores, and quality of life. Furthermore, the lymph node dissection (LND) yield and 3-year survival were equivalent ${ }^{[14,16,17]}$. However, the two-dimension view, reduced eye-hand coordination, narrow operative field, restricted freedom of movement of operative instruments, moving targets, and nearby vital structures are all limitations such that MIE remains a highly complex procedure to be mastered by the surgeon ${ }^{[8,18]}$. For example, the learning curve for an intrathoracic anastomosis was 119 cases when the incidence of 
Table 2. Characteristics of each approach to esophagectomy

\begin{tabular}{|c|c|c|c|}
\hline & OE & MIE & RAMIE \\
\hline Difficulty level of technique & Relatively easy & Highly complex & Easier than MIE \\
\hline Special points & $\begin{array}{l}\text { Conventional operative method } \\
\text { with a lot of history } \\
\text { Gold standard method }\end{array}$ & $\begin{array}{l}\text { Better vision } \\
\text { A two-dimensional view } \\
\text { Reduced eye-hand coordination } \\
\text { Restricted range of movement }\end{array}$ & $\begin{array}{l}\text { Zoomed-in enhanced three- } \\
\text { dimensional vision } \\
\text { Better overview } \\
\text { Increased range of movement } \\
\text { Tremorless actions } \\
\text { Flexible endo-wrists }\end{array}$ \\
\hline Ergonomic conditions & Normal & Worst & Best \\
\hline Blood loss & More & Less & Least \\
\hline Operative time & Shorter & Longer & Longer \\
\hline Postoperative pain score & High & Lower & Lower \\
\hline $\begin{array}{l}\text { Postoperative respiratory } \\
\text { complications }\end{array}$ & More & Less & Less \\
\hline $\begin{array}{l}\text { Difficulty and exactness of } \\
\text { upper mediastinum lymph }\end{array}$ & Difficult to access & $\begin{array}{l}\text { More challenging maneuver than } \\
\text { OE }\end{array}$ & Easier than MIE \\
\hline node dissection & Equivalent & Equivalent & More exact \\
\hline $\begin{array}{l}\text { Postoperative recurrent } \\
\text { laryngeal nerve paralysis }\end{array}$ & Equivalent & Equivalent & Reduced \\
\hline $\begin{array}{l}\text { Intrathoracic hand-sewn } \\
\text { anastomosis }\end{array}$ & Difficult & The most difficult & Easy compared to MIE \\
\hline $\begin{array}{l}\text { Acute immunological } \\
\text { response }\end{array}$ & More & Less & Same as total MIE \\
\hline Functional recovery & Slowest & Fast & Same as total MIE \\
\hline Length of hospital stay & Longest & Short & Same as total MIE \\
\hline Mortality & Equivalent & Equivalent & Equivalent \\
\hline Cost & Equivalent & Equivalent & Highest \\
\hline Survival & Equivalent & Equivalent & Equivalent \\
\hline
\end{tabular}

OE: open esophagectomy; MIE: minimum invasive esophagectomy; RAMIE: robot-assisted minimally invasive esophagectomy

anastomotic leakage was the determining parameter (the anastomotic leakage rate dropped from $18.8 \%$ to $4.5 \%)^{[18]}$. The learning phase of MIE was also considered to be a likely explanation for the higher reoperation rates as compared to OE in multiple population-based studies ${ }^{[19-22]}$. This may explain the findings from a survey amongst esophageal surgeons in 2014, which showed that only $43 \%$ of the respondents reported MIE as their preferred approach ${ }^{[23]}$. Indeed, due to its high technical complexity, MIE has not been adopted as the standard approach for esophageal cancer. These issues are summarized in Table 2.

A hybrid MIE (HMIE), which combines laparoscopy with a conventional thoracotomy, or combines a thoracoscopy with a conventional laparotomy, has been suggested as an alternative to total MIE ${ }^{[24]}$. Messager et al ${ }^{[25]}$ reported that patients undergoing HMIE showed less mortality at both 30 (3.3\% vs. 5.7\%) and 90 days $(6.9 \%$ vs. $10 \%)$ when compared to OE. In addition, Mariette et al. ${ }^{[26]}$ reported a randomized phase III trial (MIRO trial), which found that HMIE had a lower incidence of perioperative complications (36\% vs. 64\%), especially pulmonary complications (18\%vs. 30\%), with equivalent 3-year survival (67\% vs. $55 \%)$ when compared to OE. Studies comparing HMIE with total MIE are scarce. In one study, however, Bonavina et al. ${ }^{[27]}$ compared a series of 80 total MIE versus 80 HMIE patients and found no differences in early postoperative complications or mortality. In addition, Grimminger et al. ${ }^{[28]}$ reported a series of 75 patients (HMIE 25, total MIE 25, RAMIE 25), which showed comparable morbidity and short-term outcomes in the three groups, although the total minimally invasive approaches appear to be associated with a lower incidence of complications such as pneumonia and wound infections. Those studies showed that although HMIE is a transitional operative method between OE and total MIE, because of its relatively lower difficulty level, somewhat reduced invasiveness and satisfactory clinical outcomes, it is a valuable operative method worth being performed.

To overcome the disadvantages of total MIE and HMIE, a robotic surgical system was developed and applied clinically. Transhiatal RAMIE was first introduced in $2003^{[11]}$, and transthoracic RAMIE 
was introduced a year later ${ }^{[12]}$. Although RAMIE is still under development, it is now described as a promising minimally invasive operative method with short-term and long-term clinical outcomes that are equivalent to (or perhaps better than) those achieved with OE and MIE [Table 2] ${ }^{[29]}$. In a US report, $32.1 \%$ of esophageal cancer patients were treated with MIE. Of these, $19.6 \%$ were RAMIE ${ }^{[30]}$. In that report, no differences in postoperative mortality or disease-free survival was noted between MIE and RAMIE $^{[30]}$. Nevertheless, given the many unique advantages of the robot, it is expected to decrease the morbidity and mortality rates of surgery for esophageal cancer and to improve oncological outcomes. Results of the recently published ROBOT trial showed improved clinical outcomes with reduced surgical and cardiopulmonary complication rates, reduced pain and improved functional outcomes with RAMIE as compared to $\mathrm{OE}^{[31]}$. Moreover, RAMIE was associated with less intraoperative blood loss, lower postoperative pain scores, faster functional recovery, and better quality of life when compared to $\mathrm{OE}^{[31]}$. Lymph node yield and overall survival did not differ between the two approaches, indicating that RAMIE offers short-term benefits while maintaining the high oncological standards. Needless to say, evidence remains weak due to limited RCT results, and more RCT studies are still needed.

Additionally, Yun et al. ${ }^{[32]}$ showed that RAMIE is also safe and feasible for use with patients who have received neoadjuvant chemoradiotherapy for locally advanced esophageal cancer, with postoperative mortality and morbidity rates comparable to that in OE. Another recently published study compared the clinical benefits of RAMIE with conventional OE. They showed that RAMIE could be a better surgical option for selected esophageal squamous cell carcinoma patients, offering both short-term and long-term benefits ${ }^{[33]}$. Although both the short-term and long-term outcomes of RAMIE appear equivalent to MIE in most studies, one paper showed that RAMIE for esophageal cancer patients with node-positive disease in the superior mediastinum is associated with increased mortality $(7.5 \%)$ and morbidity ${ }^{[34]}$.

\section{LYMPH NODE DISSECTION IN RAMIE}

The number of lymph nodes removed is a key factor contributing to the improved survival of esophageal cancer patients ${ }^{[35]}$. LND along the recurrent laryngeal nerve (RLN) is considered beneficial; however, RLN LND is frequently complicated by RLN palsy $(20 \%-80 \%)$, which is especially common on the left side. Early meta-analysis studies showed that, unfortunately, MIE does not reduce the rates of postoperative RLN palsy following RLN LND ${ }^{[36-38]}$. On the other hand, RAMIE has several advantages for LND, especially RLN LND [Table 2]. The ROBOT trial showed that a mean of 27 and 25 lymph nodes were harvested in RAMIE and OE, respectively (not significantly different) ${ }^{[31]}$, which demonstrated that robotic surgery is at least comparable to open surgery for retrieving a sufficient number of lymph nodes. Although most early studies have found that the lymph node yield with RAMIE and MIE are similar ${ }^{[39-41]}$, in two recent series in which RAMIE and MIE were applied to upper mediastinal LND, markedly larger numbers of lymph nodes were harvested with RAMIE (median 37-49 vs. 19-21) ${ }^{[42,43]}$. In addition, when Motoyama et al. ${ }^{[4]}$ compared the number of lymph nodes dissected from around the left RLN, they found that significantly more lymph nodes were dissected with RAMIE than MIE (median 6 vs. 4). This indicates that a robot-assisted surgical system may enable more extensive dissection of lymph nodes around the left RLN. Similarly, Park et al. ${ }^{[42]}$ demonstrated that the total number of dissected lymph nodes was significantly greater in the RAMIE group $(37.3 \pm 17.1$ vs. $28.7 \pm 11.8 ; P=0.003)$, and intergroup differences were significant for the number of lymph nodes dissected from both the upper mediastinum (RAMIE: $10.7 \pm 9.7$ vs. MIE: $6.3 \pm 9.3, P=$ 0.032 ) and abdomen (RAMIE: $12.2 \pm 8.7 v$ s. MIE: $7.8 \pm 7.1, P=0.007$ ). The five-year overall survival did not differ between the two groups (RAMIE: $69 \%$ vs. MIE: $59 \%, P=0.737$ ). Deng et al. ${ }^{[45]}$ showed that RAMIE may have an advantage for lymphadenectomy (mean: $20.6 \pm 8.8 \mathrm{vs} .17 .9 \pm 7.7 ; P=0.048$ ) over MIE without increasing the risk of major postoperative complications. A recent propensity-matched analysis of patients undergoing modified Ivor Lewis esophagectomy also showed that the median total lymph node yield was 27 (range 13-84) in the RAMIE group compared to 23 in the MIE group (range 11-48). With a $P$-value of 0.053 , their results suggest a trend towards improved lymphadenectomy with RAMIE ${ }^{[46]}$. These studies 
Table 3. Intrathoracic anastomosis in RAMIE

\begin{tabular}{|c|c|c|}
\hline Intrathoracic anastomosis methods & Merits & Limitations \\
\hline Hand-sewn & $\begin{array}{l}\text { Can take full advantage of robot-assisted } \\
\text { hand-sewing. } \\
\text { Can be performed when the length is } \\
\text { insufficient for staple anastomosis }\end{array}$ & $\begin{array}{l}\text { Operative field is not satisfactory in the } \\
\text { posterior wall anastomosis }\end{array}$ \\
\hline $\begin{array}{l}\text { Overlap } \\
(\text { linear stapler } \times 1)+\text { Hand-sewn }\end{array}$ & $\begin{array}{l}\text { No need for additional mini-thoracotomy. } \\
\text { Lower occurrence of stenosis. } \\
\text { Can save stapler. } \\
\text { Can take full advantage of robot-assisted } \\
\text { hand-sewing }\end{array}$ & $\begin{array}{l}\text { Cannot completely remove tissue poorly } \\
\text { supplied with blood. } \\
\text { Need a longer tubular stomach and esophageal } \\
\text { end than circular stapler }\end{array}$ \\
\hline $\begin{array}{l}\text { Function } \\
\text { (linear stapler } \times 2 \text { ) }\end{array}$ & No need for additional mini-thoracotomy & $\begin{array}{l}\text { Need a longer tubular stomach and esophageal } \\
\text { end. } \\
\text { Cannot completely remove tissue poorly } \\
\text { supplied with blood }\end{array}$ \\
\hline $\begin{array}{l}\text { Triangular stapling } \\
(\text { linear stapler } \times 3 \text { ) }\end{array}$ & $\begin{array}{l}\text { A reportedly lower rate of anastomotic } \\
\text { complications. } \\
\text { Lower occurrence of stenosis }\end{array}$ & $\begin{array}{l}\text { The need to intrathoracically staple three times } \\
\text { in three directions is a technical challenge }\end{array}$ \\
\hline Circular stapler & $\begin{array}{l}\text { Relatively easy to perform. } \\
\text { Can completely remove tissue poorly supplied } \\
\text { with blood }\end{array}$ & $\begin{array}{l}\text { Need an additional mini-thoracotomy. } \\
\text { Need an extra circular stapler. } \\
\text { Higher occurrence of stenosis }\end{array}$ \\
\hline
\end{tabular}

RAMIE: robot-assisted minimally invasive esophagectomy

demonstrate that RAMIE may be more effective for extensive LND than MIE or OE. Recurrent nerve palsy is a complication that is especially associated with lymph node dissection in the superior mediastinum. In the ROBOT trial, the recurrent nerve palsy rate was $9 \%{ }^{[31]}$. However, Park et al. ${ }^{[47]}$ showed a significant learning curve on RLN palsy rates, which dropped from 55\% to $0 \%$ after performing 20 cases in their study. The length of the learning curve for RAMIE has been reported to be $20-70$ cases $^{[8,18]}$.

\section{ROBOTIC INTRATHORACIC ANASTOMOSIS}

The robotic intrathoracic anastomosis can be hand-sewn or performed with linear or circular staplers. Although complete hand-sewing takes full advantage of robot assistance, it appears posterior wall anastomoses are technically challenging because of the deep and narrow operative field ${ }^{[48]}$. Wang et al. ${ }^{[49]}$ showed side-to-side anastomosis to be a promising approach with the advantages of there being no need for additional mini-thoracotomy and a lower incidence of stenosis. In their report, the authors also emphasized the usefulness of the barbed knotless suture. Another recent study reported similar satisfactory outcomes with end-to-side anastomosis ${ }^{[50]}$. Those authors concluded that end-to-side anastomosis requires a shorter length of the esophageal end, and section with poor blood supply was removed by a second stapler, which may ensure a good blood supply to the anastomosis. Triangular stapling is another anastomotic technique, which is reportedly associated with a lower rate of anastomotic complications ${ }^{[51]}$. However, stapling three times in three directions would seem to present a great technical challenge intrathoracically. Recently, Han et al. ${ }^{[52]}$ reviewed diverse ways of intrathoracic anastomosis. Among these anastomotic methods, mortality was equivalent, but the anastomotic leak rates differed. Further large clinical trials are still needed. In general, each method has its merits and demerits. Surgeons should determine the anastomotic method of every single case with the final aim of maximizing patient benefits. The methods used for anastomosis in RAMIE are summarized in Table 3.

\section{TRANSTHORACIC VS. TRANSHIATAL RAMIE}

As with MIE, different variations of RAMIE have been established. Transthoracic RAMIE is one of the most commonly used approaches. It has a wide operative field, and after posterior and middle mediastinal LND, superior mediastinal LND can be performed in this operative field. However, destruction of the thoracic wall and pleura are unavoidable and differential lung ventilation is still needed. In 2003, Talamini et al. ${ }^{[10]}$ reported the first series of transhiatal RAMIE. Conventional transhiatal MIE has been proven as a less 
Table 4. Transthoracic vs. transhiatal route in RAMIE

\begin{tabular}{|c|c|c|}
\hline RAMIE & Merits & Limitations \\
\hline Transthoracic & $\begin{array}{l}\text { Wide operative field. } \\
\text { Superior mediastinum lymph node dissection can be } \\
\text { performed in the same operative field }\end{array}$ & $\begin{array}{l}\text { Thoracic wall and pleura destruction are unavoidable. } \\
\text { Differential lung ventilation is still needed in most case }\end{array}$ \\
\hline Transhiatal & $\begin{array}{l}\text { No need for thoracic wall destruction. } \\
\text { No pleurotomy. } \\
\text { No need of differential lung ventilation. } \\
\text { No need for a change in body position. } \\
\text { Almost no postoperative respiratory complications }\end{array}$ & $\begin{array}{l}\text { Narrow operative field. } \\
\text { Need a decent experience for mediastinum lymph node } \\
\text { dissection under mediastinoscopy }\end{array}$ \\
\hline
\end{tabular}

RAMIE: robot-assisted minimally invasive esophagectomy

invasive operative method but oncologically inferior to radical esophagectomy ${ }^{[53]}$. Although lymph node dissection of the lower mediastinal field is considered to be equivalent to radical esophagectomy, when it comes to the middle mediastinal field, it shows shortages because conventional endoscopic devices suffer from the paralleled right- and left-hand in the deep narrow operative fields. Meanwhile, the robot has articulated instruments and enhanced three-dimensional magnified view, which can move freely in the deep narrow cavity. It has been proven that RAMIE can overcome the limitations of the conventional transhiatal MIE and can dissect lymph nodes equivalent to radical esophagectomy ${ }^{[54]}$. Yoshimura et al. ${ }^{[55]}$ showed that transhiatal RAMIE is associated with fewer pulmonary complications (0\%) and better postoperative quality of life. However, it requires two LND steps. Posterior and middle mediastinal LND is performed using transhiatal RAMIE, followed by cervical mediastinoscopy for superior mediastinal LND. Mori et al. ${ }^{[56]}$ showed that the radicality of transmediastinal esophagectomy is equivalent to that of transthoracic esophagectomy in terms of the number of harvested lymph nodes and the pathology of surgical margins. Similarly, postoperative pneumonia did not occur in the transhiatal group. Although short-term and long-term outcomes were reported to not be inferior, due to the narrow operative field with the transhiatal procedure and mediastinoscopy, transhiatal RAMIE appears to be a more complex procedure. RAMIE operative routes are summarized in Table 4.

\section{OPERATIVE POSITIONS IN RAMIE}

Acute lung injury occurs in $25 \%-30 \%$ of patients after transthoracic esophagectomy, and single lung ventilation has been implicated in its pathogenesis ${ }^{[57]}$. Until recently, RAMIE has been performed with the patient in the left lateral decubitus position in a setting of single-lung ventilation. Full lateral decubitus position with a cephalic parallel approach was reported to save some operative time $(381 \pm 57.7 \mathrm{~min})^{[58]}$. However, this approach requires total lung collapse and is therefore, often accompanied by serious pulmonary complications. To overcome the disadvantages of differential ventilation, Palanivelu et al. ${ }^{[59]}$ performed MIE with patents in a prone position. With their large patient cohort, they found that the prone position takes advantage of gravity to displace the lung from the dorsal thoracic structures and the esophagus, and that it has lower respiratory complications and shorter operative times due to the excellent exposure of the operative field and the better ergonomics for the surgeon. Sometimes, the vertebral column may obstruct the view of the operative field. Ruurda et al ${ }^{[60]}$ reviewed the application of the prone position in RAMIE, with the patient cart of the robot system standing on the patient's side and extending its arms in a direction crossing the longitudinal axis of the patient. In the subsequent abdominal phase, the patient cart must be repositioned in front of the patient's head. This patient cart repositioning is time-consuming ${ }^{[58]}$. On the other hand, urgent conversion to a classic thoracotomy, if needed, is probably more difficult with the prone position ${ }^{[61]}$. As a solution to overcome this problem, whilst retaining the benefits of the prone position, a relatively complicated position, a modified semi-prone position has been adopted by surgeons around the world ${ }^{[62]}$. Operative positions are summarized in Table 5. 
Table 5. Operative positions in RAMIE

\begin{tabular}{lll}
\hline & \multicolumn{1}{c}{ Merits } & \multicolumn{1}{c}{ Limitations } \\
\hline Left lateral decubitus position & $\begin{array}{l}\text { Similar to open resection and does not require } \\
\text { repositioning in the case of a conversion to open }\end{array}$ & $\begin{array}{l}\text { Need single-lung ventilation with more } \\
\text { postoperative pulmonary complications. }\end{array}$ \\
Prone position & $\begin{array}{l}\text { Takes advantage of gravity to displace the lung from the Need repositioning in the case of a conversion } \\
\text { dorsal thoracic structures and the esophagus. }\end{array}$ & to open surgery \\
& Excellent exposure of the operative field. & \\
& Allows for double-lung ventilation with less & Relatively complicated \\
Semi-prone position & Has benefits of both the prone position and left lateral & \\
\hline
\end{tabular}

RAMIE: robot-assisted minimally invasive esophagectomy

Table 6. Prospects of RAMIE

\begin{tabular}{ll}
\hline 1 & Tactile function \\
2 & Forceps tip shape change function \\
3 & Automatic forceps switch function \\
4 & Flexible camera \\
5 & Artificial intelligence \\
6 & Miniaturized operating robot body and wrist \\
7 & Break the monopoly of the Da Vinci system \\
\hline
\end{tabular}

RAMIE: robot-assisted minimally invasive esophagectomy

\section{PROSPECTS FOR RAMIE}

Although RAMIE has a number of advantages that can overcome the shortcomings of MIE, there are still many problems that need to be resolved [Table 6]. For example, to perform surgery more safely, if possible we would like to add tactile function to the robot. To shorten the operative time, a forceps tip with shape changing function, automatic forceps switching function, and flexible camera are expected. Artificial intelligence is another exciting feature that is being developed. To reduce interference, we are looking forward to the development and manufacture of an operating robot with a miniaturized body and wrists. In addition, to break the monopoly of the Da Vinci system, many surgical robot companies worldwide are working on the development and manufacture of new robot surgery systems, which could bring lower costs.

\section{DECLARATIONS}

\section{Authors' contributions}

Made substantial contributions to the conception and design of the study and performed data analysis and interpretation: Liu J, Motoyama S

Performed data acquisition, as well as provided administrative, technical, and material support: Sato Y, Wakita A, Kawakita Y, Nagaki Y, Fujita H, Imai K, Minamiya Y

\section{Availability of data and materials}

Not applicable.

\section{Financial support and sponsorship}

None.

\section{Conflicts of interest}

All authors declared that there are no conflicts of interest. 


\section{Ethical approval and consent to participate}

Not applicable.

\section{Consent for publication}

Not applicable.

\section{Copyright}

(c) The Author(s) 2020.

\section{REFERENCES}

1. Torre LA, Siegel RL, Ward EM, Jemal A. Global cancer incidence and mortality rates and trends--an update. Cancer Epidemiol Biomarkers Prev 2016;25:16-27.

2. Hulscher JB, van Sandick JW, de Boer AG, Wijnhoven BP, Tijssen JG, et al. Extended transthoracic resection compared with limited transhiatal resection for adenocarcinoma of the esophagus. N Engl J Med 2002;347:1662-9.

3. Takeuchi H, Miyata H, Gotoh M, Kitagawa Y, Baba H, et al. A risk model for esophagectomy using data of 5354 patients included in a Japanese nationwide web-based database. Ann Surg 2014;260:259-66.

4. Chen MF, Yang YH, Lai CH, Chen PC, Chen WC. Outcome of patients with esophageal cancer: a nationwide analysis. Ann Surg Oncol 2013;20:3023-30.

5. Kato H, Nakajima M. Treatments for esophageal cancer: a review. Gen Thorac Cardiovasc Surg 2013;61:330-5.

6. Cuschieri A, Shimi S, Banting S. Endoscopic oesophagectomy through a right thoracoscopic approach. J R Coll Surg Edinb 1992;37:7-11.

7. van Hillegersberg R, Boone J, Draaisma WA, Broeders IA, Giezeman MJ, et al. First experience with robot-assisted thoracoscopic esophagolymphadenectomy for esophageal cancer. Surg Endosc 2006;20:1435-9.

8. Kingma BF, de Maat MFG, van der Horst S, van der Sluis PC, Ruurda JP, et al. Robot-assisted minimally invasive esophagectomy (RAMIE) improves perioperative outcomes: a review. J Thorac Dis 2019;11:S735-42.

9. Marescaux J, Leroy J, Gagner M, Rubino F, Mutter D, et al. Transatlantic robot-assisted telesurgery. Nature 2001;413:379-80.

10. Talamini MA, Chapman S, Horgan S, Melvin WS; Academic robotics group. A prospective analysis of 211 robotic-assisted surgical procedures. Surg Endosc 2003;17:1521-4.

11. DePaula AL, Hashiba K, Ferreira EA, de Paula RA, Grecco E. Laparoscopic transhiatal esophagectomy with esophagogastroplasty. Surg Laparosc Endosc 1995;5:1-5.

12. Kernstine KH, DeArmond DT, Karimi M, Van Natta TL, Campos JH, et al. The robotic, 2-stage, 3-field esophagolymphadenectomy. J Thorac Cardiovasc Surg 2004;127:1847-9.

13. Luketich JD, Alvelo-Rivera M, Buenaventura PO, Christie NA, McCaughan JS, et al. Minimally invasive esophagectomy: outcomes in 222 patients. Ann Surg 2003;238:486-94; discussion 494-5.

14. Biere SS, van Berge Henegouwen MI, Maas KW, Bonavina L, Rosman C, et al. Minimally invasive versus open oesophagectomy for patients with oesophageal cancer: a multicentre, open-label, randomised controlled trial. Lancet 2012;379:1887-92.

15. van der Sluis PC, Schizas D, Liakakos T, van Hillegersberg R. Minimally Invasive Esophagectomy. Dig Surg 2020;37:93-100.

16. Maas KW, Biere SS, van Hoogstraten IM, van der Peet DL, Cuesta MA. Immunological changes after minimally invasive or conventional esophageal resection for cancer: a randomized trial. World J Surg 2014;38:131-7.

17. Straatman J, van der Wielen N, Cuesta MA, Daams F, Roig Garcia J, et al. Minimally invasive versus open esophageal resection: threeyear follow-up of the previously reported randomized controlled trial: the TIME trial. Ann Surg 2017;266:232-6.

18. van Workum F, Stenstra MHBC, Berkelmans GHK, Slaman AE, van Berge Henegouwen MI, et al. Learning curve and associated morbidity of minimally invasive esophagectomy: a retrospective multicenter study. Ann Surg 2019;269:88-94.

19. Takeuchi H, Miyata H, Ozawa S, Udagawa H, Osugi H, et al. Comparison of short-term outcomes between open and minimally invasive esophagectomy for esophageal cancer using a nationwide database in Japan. Ann Surg Oncol 2017;24:1821-7.

20. Sihag S, Kosinski AS, Gaissert HA, Wright CD, Schipper PH. Minimally invasive versus open esophagectomy for esophageal cancer: a comparison of early surgical outcomes from the society of thoracic surgeons national database. Ann Thorac Surg 2016;101:1281-8; discussion 1288-9.

21. Seesing MFJ, Gisbertz SS, Goense L, van Hillegersberg R, Kroon HM, et al. A propensity score matched analysis of open versus minimally invasive transthoracic esophagectomy in the netherlands. Ann Surg 2017;266:839-46.

22. Mamidanna R, Bottle A, Aylin P, Faiz O, Hanna GB. Short-term outcomes following open versus minimally invasive esophagectomy for cancer in England: a population-based national study. Ann Surg 2012;255:197-203.

23. Haverkamp L, Seesing MF, Ruurda JP, Boone J, V Hillegersberg R. Worldwide trends in surgical techniques in the treatment of esophageal and gastroesophageal junction cancer. Dis Esophagus 2017;30:1-7.

24. Briez N, Piessen G, Bonnetain G, Brigand C, Carrere N, et al. Open versus laparoscopically-assisted oesophagectomy for cancer: a multicentre randomised controlled phase III trial - the MIRO trial. BMC Cancer, 2011;11:310.

25. Messager M, Pasquer A, Duhamel A, Caranhac G, Piessen G, et al; FREGAT working groupFRENCH. Laparoscopic gastric mobilization reduces postoperative mortality after esophageal cancer surgery: a french nationwide study. Ann Surg 2015;262:817-22; discussion 822-3.

26. Mariette C, Markar SR, Dabakuyo-Yonli TS, Meunier B, Pezet D, et al; Fédération de Recherche en Chirurgie (FRENCH) and French 
Eso-Gastric Tumors (FREGAT) Working Group. Hybrid minimally invasive esophagectomy for esophageal cancer. N Engl J Med 2019;380:152-62.

27. Bonavina L, Scolari F, Aiolfi A, Bonitta G, Sironi A, et al. Early outcome of thoracoscopic and hybrid esophagectomy: propensitymatched comparative analysis. Surgery 2016;159:1073-81.

28. Grimminger PP, Tagkalos E, Hadzijusufovic E, Corvinus F, Babic B, et al. Change from hybrid to fully minimally invasive and robotic esophagectomy is possible without compromises. Thorac Cardiovasc Surg 2019;67:589-96.

29. Biebl M, Andreou A, Chopra S, Denecke C, Pratschke J. Upper gastrointestinal surgery: robotic surgery versus laparoscopic procedures for esophageal malignancy. Visc Med 2018;34:10-5.

30. Weksler B, Sullivan JL. Survival after esophagectomy: a propensity-matched study of different surgical approaches. Ann Thorac Surg 2017;104:1138-46.

31. van der Sluis PC, van der Horst S, May AM, Schippers C, Brosens LAA, et al. Robot-assisted minimally invasive thoracolaparoscopic esophagectomy versus open transthoracic esophagectomy for resectable esophageal cancer: a randomized controlled trial. Ann Surg 2019;269:621-30.

32. Yun JK, Lee IS, Gong CS, Kim BS, Kim HR, et al. Clinical utility of robot-assisted transthoracic esophagectomy in advanced esophageal cancer after neoadjuvant chemoradiation therapy. J Thorac Dis 2019;11:2913-23.

33. Yun JK, Chong BK, Kim HJ, Lee IS, Gong CS, et al. Comparative outcomes of robot-assisted minimally invasive versus open esophagectomy in patients with esophageal squamous cell carcinoma: a propensity score-weighted analysis. Dis Esophagus 2020;33:doz071.

34. van der Horst S, de Maat MFG, van der Sluis PC, Ruurda JP, van Hillegersberg R. Extended thoracic lymph node dissection in roboticassisted minimal invasive esophagectomy (RAMIE) for patients with superior mediastinal lymph node metastasis. Ann Cardiothorac Surg 2019;8:218-25.

35. Visser E, van Rossum PSN, Ruurda JP, van Hillegersberg R. Impact of lymph node yield on overall survival in patients treated with neoadjuvant chemoradiotherapy followed by esophagectomy for cancer: a population-based cohort study in the Netherlands. Ann Surg 2017;266:863-9.

36. Nagpal K, Ahmed K, Vats A, Yakoub D, James D, et al. Is minimally invasive surgery beneficial in the management of esophageal cancer? A meta-analysis. Surg Endosc 2010;24:1621-9.

37. Sgourakis G, Gockel I, Radtke A, Musholt TJ, Timm S, et al. Minimally invasive versus open esophagectomy: meta-analysis of outcomes. Dig Dis Sci 2010;55:3031-40.

38. Guo W, Ma X, Yang S, Zhu X, Qin W, et al. Combined thoracoscopic-laparoscopic esophagectomy versus open esophagectomy: a metaanalysis of outcomes. Surg Endosc 2016;30:3873-81.

39. Weksler B, Sharma P, Moudgill N, Chojnacki KA, Rosato EL. Robot-assisted minimally invasive esophagectomy is equivalent to thoracoscopic minimally invasive esophagectomy. Dis Esophagus 2012;25:403-9.

40. Suda K, Ishida Y, Kawamura Y, Inaba K, Kanaya S, et al. Robot-assisted thoracoscopic lymphadenectomy along the left recurrent laryngeal nerve for esophageal squamous cell carcinoma in the prone position: technical report and short-term outcomes. World J Surg 2012;36:1608-16.

41. Zhang Y, Han Y, Gan Q, Xiang J, Jin R, et al. Early outcomes of robot-assisted versus thoracoscopic-assisted ivor lewis esophagectomy for esophageal cancer: a propensity score-matched study. Ann Surg Oncol 2019;26:1284-91.

42. Park S, Hwang Y, Lee HJ, Park IK, Kim YT, et al. Comparison of robot-assisted esophagectomy and thoracoscopic esophagectomy in esophageal squamous cell carcinoma. J Thorac Dis 2016;8:2853-61.

43. Park SY, Kim DJ, Do YW, Suh J, Lee S. The oncologic outcome of esophageal squamous cell carcinoma patients after robot-assisted thoracoscopic esophagectomy with total mediastinal lymphadenectomy. Ann Thorac Surg 2017;103:1151-7.

44. Motoyama S, Sato Y, Wakita A, Kawakita Y, Nagaki Y, et al. Extensive lymph node dissection around the left laryngeal nerve achieved with robot-assisted thoracoscopic esophagectomy. Anticancer Res 2019;39:1337-42.

45. Deng HY, Luo J, Li SX, Li G, Alai G, et al. Does robot-assisted minimally invasive esophagectomy really have the advantage of lymphadenectomy over video-assisted minimally invasive esophagectomy in treating esophageal squamous cell carcinoma? A propensity score-matched analysis based on short-term outcomes. Dis Esophagus 2019;32:doy110.

46. Tagkalos E, Goense L, Hoppe-Lotichius M, Ruurda JP, Babic B, et al. Robot-assisted minimally invasive esophagectomy (RAMIE) compared to conventional minimally invasive esophagectomy (MIE) for esophageal cancer: a propensity-matched analysis. Dis Esophagus 2020;33:doz060.

47. Park SY, Kim DJ, Kang DR, Haam SJ. Learning curve for robotic esophagectomy and dissection of bilateral recurrent laryngeal nerve nodes for esophageal cancer. Dis Esophagus, 2017;30:1-9.

48. Cerfolio RJ, Wei B, Hawn MT, Minnich DJ. Robotic esophagectomy for cancer: early results and lessons learned. Semin Thorac Cardiovasc Surg 2016;28:160-9.

49. Wang F, Zhang H, Zheng Y, Wang Z, Geng Y, et al. Intrathoracic side-to-side esophagogastrostomy with a linear stapler and barbed suture in robot-assisted Ivor Lewis esophagectomy. J Surg Oncol 2019;120:1142-7.

50. Wang Z, Zhang H, Wang F, Wang Y. Robot-assisted esophagogastric reconstruction in minimally invasive Ivor Lewis esophagectomy. J Thorac Dis 2019;11:1860-6.

51. Noshiro H, Urata M, Ikeda O, Iwasaki H, Nabae T, et al. Triangulating stapling technique for esophagogastrostomy after minimally invasive esophagectomy. Surgery 2013;154:604-10.

52. Han Y, Zhang Y, Li H. Application of different intrathoracic esophagogastric anastomosis in surgery for esophageal cancer. Zhonghua Wei 
Chang Wai Ke Za Zhi 2018;21:995-1000. (in Chinese)

53. Montenovo MI, Chambers K, Pellegrini CA, Oelschlager BK. Outcomes of laparoscopic-assisted transhiatal esophagectomy for adenocarcinoma of the esophagus and esophago-gastric junction. Dis Esophagus 2011;24:430-6.

54. DeLong JC, Kelly KJ, Jacobsen GR, Sandler BJ, Horgan S, et al. The benefits and limitations of robotic assisted transhiatal esophagectomy for esophageal cancer. J Vis Surg 2016;2:156.

55. Yoshimura S, Mori K, Yamagata Y, Aikou S, Yagi K, et al. Quality of life after robot-assisted transmediastinal radical surgery for esophageal cancer. Surg Endosc 2018;32:2249-54.

56. Mori K, Yamagata Y, Aikou S, Nishida M, Kiyokawa T, et al. Short-term outcomes of robotic radical esophagectomy for esophageal cancer by a nontransthoracic approach compared with conventional transthoracic surgery. Dis Esophagus 2016;29:429-34.

57. Baudouin SV. Lung injury after thoracotomy. Br J Anaesth 2003;91:132-42.

58. Zhu Y, Ma L, Liu L, Lin Y. Application of full lateral decubitus position with cephalic parallel approach in robotic-assisted minimally invasive esophagectomy. J Thorac Dis 2019;11:3250-6.

59. Palanivelu C, Prakash A, Senthilkumar R, Senthilnathan P, Parthasarathi R, et al. Minimally invasive esophagectomy: thoracoscopic mobilization of the esophagus and mediastinal lymphadenectomy in prone position--experience of 130 patients. J Am Coll Surg 2006;203:7-16.

60. Ruurda JP, van der Sluis PC, van der Horst S, van Hillegersberg R. Robot-assisted minimally invasive esophagectomy for esophageal cancer: a systematic review. J Surg Oncol 2015;112:257-65.

61. Markar SR, Wiggins T, Antonowicz S, Zacharakis E, Hanna GB. Minimally invasive esophagectomy: lateral decubitus vs. prone positioning; systematic review and pooled analysis. Surg Oncol 2015;24:212-9.

62. Seesing MFJ, Goense L, Ruurda JP, Luyer MDP, Nieuwenhuijzen GAP, et al. Minimally invasive esophagectomy: a propensity scorematched analysis of semiprone versus prone position. Surg Endosc 2018;32:2758-65. 